\title{
Innovations in the Management of E-Commerce Entities Operating on the Slovak Market - Analysis of Customer Interactions during the COVID-19 Pandemic
}

\author{
Frantisek Pollak ${ }^{1, *}$, Bozka Malinak $^{2}$, Peter Markovic ${ }^{3}$, Robert Vilagi ${ }^{3}$ \\ ${ }^{1}$ Institute of Technology and Business, Faculty of Corporate Strategy, Okružní 517/10, 37001 České Budějovice, Czech Republic \\ ${ }^{2}$ Acuity Engineering \& Consulting Service Ltd, 10327122 St NW, T5N1M1 Edmonton AB, Canada \\ ${ }^{3}$ University of Economics in Bratislava, Faculty of Business Management, Department of Business Finance, Dolnozemská cesta 1/b, \\ 85235 Bratislava, Slovakia
}

\begin{abstract}
This paper deals with the issue of innovation in e-commerce, specifically with the application of innovative methods of evaluating customer interactions in the environment of the virtual social network Facebook. The first part presents the results of desk research on the issue of the utilization of virtual social media Facebook in e-commerce in order to approach the knowledge base of the analysed issues. The aim of the second part of the study presented in the paper was to describe and evaluate the activities of customer groups of the five largest e-commerce entities operating in the Slovak virtual market. The data needed for the analysis were collected during the state of emergency declared in connection with the COVID-19 pandemic. From the point of view of findings, the initial trends in the customers interactions were declining online activity over the weekend and an increase in online activity at the beginning of the working week. In general, it can be stated that data were analysed in a highly non-standard market situation. With respect to the social media e-communication of selected e-commerce entities, it was possible to outline specific patterns of consumer behaviour. As a result, it was possible to create a qualitative knowledge base for further research into the impact of the COVID-19 pandemic on national and international economies, for both economics and management sciences.
\end{abstract}

Keywords: facebook; e-commerce; COVID-19; customer interactions; customer behaviour; lockdown; Slovakia; pandemic

\section{Introduction}

For almost two decades, literature [1-5] has provided estimates and predictions of the possible impact of innovations, especially e-commerce on the global market. We are confronted with concepts where traditional stores turn into a form of showroom, respectively even further in the predictions, that sales will exceed those in traditional bricks and mortar stores [6]. The customer therefore gets the space to create a product according to their ideas and according to their needs. This method gives the customer a sense of product and even brand development. Businesses therefore obtain data for the needs of targeted communication with their target groups. Based on customer behaviour, businesses then analyse customers habits, ways of preferred presentation and taste. Entrepreneurship through customer care is part of modern business strategy textbooks, where online is no longer only recommended, but rather required [7]. At the end of 2019, it was inconceivable that bricks and mortar stores could be temporarily closed by the state. The unprecedented situation of the first half of 2020 literally cleared the market in an unthinkable way. As a result, small and medium-sized companies have been faced with the difficult task of finding new ways of communicating with customers, as well as new ways of selling goods and providing services. Online business today does not fill the position of an ancillary service, but under the pressure of circumstances it has become a necessary part of the tools for the basic survival of companies across the economy. Traditional companies built on history-proven foundations and forms of sales no longer have a choice. The situation surrounding the COVID-19 pandemic has also alerted traditionalists and staunch opponents of social networks. However, it should be borne in mind that this situation is not the result of market formation or the global market economy, but an externality, the black swam that only few risk managers anticipated. From a financial point of view, the term reserve fund has taken first place in the value ranking of corporate strategy. Once a term, envisaged only by multinational companies, it has become an essential part of the financial management of small and medium-sized companies. Creating a financial reserve to cover short-term outages is also not the answer. The pandemic has created a new chapter in global risk management that is moving into the microeconomy in response to customer retention, taking into account real-time government actions. The level of preparedness of companies for unexpected circumstances will be verified only by the fact itself. If we look at the repeatability of similar externalities, we find that we have a decimal sinusoid here. This fact

\footnotetext{
* Corresponding author: frantisek.pollak@mail.vstecb.cz
} 
creates the possibility of a model of preparation for a given situation, although it should be noted that each pandemic brings new inputs to economic analysis. At present, consumers are placing greater emphasis on online communication at the level of their own comfort, whereby interactions result only from everyday needs. However, in a time of pandemic, companies are literally forced to take measures that do not come as market impulses, but rather as state regulations. All of these acts in business management function as a catalyst for innovation. Within this context, even the concept of corporate assets has become multidimensional. As part of our study, we will look at the issue of customer groups and their interactions, as a generator of additional value and competitiveness. The aim of this work is to use innovative approaches to examine and describe selected characteristics of customer behaviour in a sharply non-standard environment. The first part presents the results of desk research on the issue of the utilization of virtual social media Facebook in ecommerce in order to approach the knowledge base of the analysed issues. The aim of the second part of the study presented in this paper is to describe and evaluate the activities of customer groups of the five largest e-commerce entities operating in the Slovak virtual market during the state of emergency declared in the Slovak Republic from March to June 2020. The study itself created the opportunity to identify possible patterns of behaviour based on a sample of almost half a million customers. By seeking to create qualitative knowledge for future in-depth research into the impact of the pandemic on both national and transnational economies, the authors hope to contribute to a shift in knowledge in both economic and managerial sciences.

\subsection{Basic definition of key concepts}

\subsubsection{Concept of social networks}

At the end of the 1970s, researchers Holland and Leinhardt [8] described the starting points for social network research on the basis of individual links between various actors. Terms such as social and opinion clusters and equilibrating processes in social networks defined the basic preconditions for in-depth research Australian professor Garry Robins [9] noted that social network research is conceptually different due to its unique theoretical imperative rather than its collection of methods. It is possible to fully identify with this statement, especially if we consider the claim that network structure affects collective outcomes, and locations within networks affect actor outcomes. American researchers [10] subsequently define virtual social networks as web services, which enable individuals to:

- create a public profile within a bounded system;

- $\quad$ articulate a list of other users with whom they share a connection;

- view and traverse their list of connections within the system.

The communication element is highlighted in Macek's definition [11], according to whom virtual social networks are egocentric communication platforms, in which user profiles through which users can view profiles of other users and communicate with them, take the central position. Virtual social networks are based on a combination of different methods of communication, where sharing is the most important one. It is a public space, which allows users to fulfil social norms, express their opinions publicly, learn from reactions of others and give events and statements the value of reality by confirming them as witnesses [12]. The concept of a social network can be viewed from two perspectives. The first perspective is a part of sociology, the second is as a part of the Internet. From a sociological perspective, a social network using a sociological dictionary is defined as follows: A social network is a set of entities connected by exchange relationships. Entities form the node points of the network, while relationships are expressed by connecting lines between these points. A social network can therefore be understood as interconnected groups of people integrating and influencing each other, while the sphere of their interactions includes varied content based on common experiences, interests, religion or racial affiliation [13]. From the perspective of the Internet, a social network is defined as an Internet service that allows registered users to create and edit a personal/corporate public/non-public profile and to use it to communicate with other users, share various kinds of information, photos, videos, chat, and perform other activities [14-15]. Virtual social networks go far beyond technology and media. It is one of the most prominent sociocultural phenomena of this decade [16]. By developing new types of everyday interactions, which implies the possibility of new types of relationships, social websites like Facebook, MySpace and LinkedIn have fundamentally changed our lives and work style and the way we connect with others [17-18]. As individuals, we have two sources of personal competitive advantage: human capital and social capital. Human capital includes talent, intellect, charisma and formal authority, which is important for success, but cannot often be controlled directly. On the other hand, social capital is derived from our relationships. Research shows [10] that due to the transfer of their network to the web, people are more capable and more efficient in assembling and using social capital. Consciously or unconsciously, they use Facebook and LinkedIn, for example, as a tool for maximizing their social capital from relationships:

- $\quad$ private information - frequent, informal communication which happens on social networks, contains private information. The emotional relationship between individuals on a social network is transferred to their offline relationships and therefore increases the likelihood of information exchange; 
- $\quad$ varying offer of skills - HR managers, recruiters and others can simply access LinkedIn or Facebook to search the profiles of and view the activities of those members who have the corresponding skills required and contact them directly;

- $\quad$ energy and attention of others - instead of filling their own network with spam in the form of bulk mail, social network members can passively offer opportunities on their profiles in the form of status and therefore have the approaching parties articulate their interest themselves.

\subsubsection{Concept of e-communication}

Virtual social networks are based on a combination of different methods of communication, where sharing is the most important one. It is a public space, which allows users to fulfil social norms, express their opinions publicly, learn from the reactions of others and give events and statements the value of reality by confirming them as witnesses [10]. The most important advantage of online social networks is social capital, which is a result of the formation and maintenance of interpersonal relationships [19]. From another perspective, the main reason for using online social networks is keeping in touch with friends and acquaintances. This is also true of our memories. Four of the most common reasons for users are contact with friends, planning with friends, organizing events and getting advice and recommendations. Companies and other institutions may use online social networks to, for example, inform about interesting events because sending invitations to interesting events is one of their basic functionalities [20]. Social networks are also an effective tool for public relations. If users are offered an interesting topic, they can very efficiently spread all types of petitions and similar initiatives through social networks. Social networks also enables companies to bring brands closer to their customers, increase their popularity and strengthen their image [21]. The functionality of social networks enables users to add their favourite brands to their personal profiles. Foreign research suggests that fans of brands on online social networks are much more likely to buy a brand or recommended it to their friends [22-23]. Marketers need to be where their customers and potential customers are, which is, more and more frequently, on social networking sites [24]. Sites such as Facebook have hundreds of millions of active users. A billion minutes are spent on Facebook every day. Social networks are a rapidly growing global phenomenon that extends across all continents [17].

\section{Methodology}

As mentioned in the introduction, e-commerce is increasingly becoming an integral part of the core business of most businesses operating in an increasingly globalized market. Under normal circumstances, the transition to e-commerce is a continuous process, which is necessary in the long run, but which is not yet conditioning the very existence of companies in the short term. However, what if a large part of the traditional B2C market suddenly collapses? How will the absence or a significant reduction in the supply of bricks and mortar stores complicate the already extremely difficult situation of managing an online reputation? On 15th March 2020, a state of emergency was declared in the Slovak Republic in connection with a pandemic caused by a new coronavirus. A lockdown saw bricks and mortar stores close and a significant slowdown in the economy. This hitherto unthinkable state created specific conditions in which it was possible to observe on a daily basis highly non-standard situations, which created an environment for research in almost all areas of scientific research.

The aim of this work is to use innovative approaches to examine and describe selected characteristics of customer behaviour in a strictly non-standard environment. The first part presents the results of desk research on the issue of the utilization of virtual social media Facebook in e-commerce in order to approach the knowledge base of the analysed issues. The aim of the second part of the study presented in this paper is to describe and evaluate the activities of customer groups of the five largest e-commerce entities operating in the Slovak virtual market [25] during the state of emergency declared in the Slovak Republic from March to June 2020.

In the period from 15th March to 13th June 2020, the interactions of customer groups were systematically recorded on a daily basis in the environment of the virtual social network Facebook.

The customer groups in question were fans of the profiles of the five largest e-commerce operators in the Slovak market.

For the purpose of the analysis, the interactions of these customer groups are represented by the interactions of the individuals to contributions that have a marketing communication nature, and which the subject / profile manager of the subject published during the observed period on the official profile of the monitored company.

The reactions took the following forms:

- Like;

- Comment;

- Share.

The collected data were classified, evaluated by means of descriptive statistics and then graphically interpreted in order to illustrate the key findings. The analysis process as well as the results thereof are subsequently discussed. 
The study itself created the opportunity to identify possible patterns of behaviour based on a sample of almost half a million customers of the five largest e-commerce operators in the Slovak Republic. By seeking to create qualitative knowledge for future in-depth research into the impact of the pandemic on both national and transnational economies, the authors hope to contribute to a shift in knowledge in both economic and managerial sciences.

\section{Results and Discussion}

The specific situation created a model environment for examining the specifics of customer behaviour. As we stated in the introduction of this article, social media communication, as an integral part of e-commerce, gives companies a wide range of advantages over traditional forms of trading. This includes, among other things, the advantage of real-time feedback. Academics and practitioners alike are increasingly being confronted by the fact that the value of a company no longer lies in its economic indicators, but in its benefits to society.

Customers have transformed themselves from nameless consumers into active followers, into communities that have their own dynamics, express assertive feedback, and largely determine the value of an organization through their attitudes, especially if it is a publicly traded organization. Examples are the showcases of western economies such as Microsoft or Google. At this point, we must ask the question, how does the collapse of the traditional consumer supply chain, forced by the lockdown of the economy, affect the interactions of these active and assertive communities?

In the following table we present the basic indicators of the activities of the monitored entities on the basis of the accumulated number of posts on the Facebook profiles of the five largest operators of e-commerce services in the Slovak Republic, namely: Alza.sk, Mall.sk, nay.sk, Martinus.sk and Bonprix SR. In addition, the basic numbers of user interactions in relation to those activities were calculated using descriptive statistics. The results are as follows:

Table 1. Indicators of overall activity

\begin{tabular}{|l|c|c|c|c|c|}
\hline & $\begin{array}{c}\text { Number of posts } \\
(\mathbf{n})\end{array}$ & $\begin{array}{c}\text { Number of likes } \\
(\mathbf{n})\end{array}$ & $\begin{array}{c}\text { Number of comments } \\
(\mathbf{n})\end{array}$ & $\begin{array}{c}\text { Number of shares } \\
(\mathbf{n})\end{array}$ & $\begin{array}{c}\text { Number of days. } \\
(\mathbf{n})\end{array}$ \\
\hline SUM & 668 & 171,138 & 59,684 & 8,795 & 91 \\
\hline Daily Max & 14 & 6,497 & 5,854 & 1,152 & 91 \\
\hline Daily Min & 3 & 52 & 0 & 3 & 91 \\
\hline Daily Average & 7 & 1,881 & 656 & 97 & 91 \\
\hline Daily Modus & 9 & 910 & 488 & 6 & 91 \\
\hline Daily Median & 7 & 1,016 & 358 & 29 & 91 \\
\hline
\end{tabular}

Legend: Bonprix had a geographically allocated profile which displayed only the total number of fans globally for all geographic locations together, i.e. more than six million fans. For our purposes, we estimated the number of fans proportionally and added this to the measured number of fan groups of the other monitored entities. The total number is therefore only an approximate estimated value.

\section{Source: Authors.}

In the monitored period of 91 days, we recorded almost a quarter of a million user interactions for a total of 668 posts/contributions published on the profiles of the subjects. If the total number of fans of the subjects is taken into account, it is possible to state that the user groups are relatively active. During the period under review, a total of almost 6,500 likes, 6,000 comments and more than 1,100 hundred shares were cumulatively recorded as a maximum value in one day. These are moderately high numbers when compared to the nature and value of the type of interactions identified in reference research carried out in the past [19].

A more detailed look at the numbers reveals that even among the best, there are still entities that do not communicate with their customer groups on a regular daily basis, while regular and targeted communication is essential for both creating and subsequently building relationships in the online environment. At the same time, it is possible to identify that from the point of view of user interactions there is room for improvement. In the case of the more active e-commerce entities, user responses were initiated by regular activities of an active marketing communication nature, such as competitions.

On the other hand, a significant percentage of posts received only few or no responses from customer groups. It should be noted that marketing activities, unless it is an activity of a social marketing nature, which do not instigate a customer response, are either incorrectly implemented or insufficiently prepared. This represents a wasted opportunity and an inefficient use of resources. Especially in turbulent times, it is essential to maximize efforts towards efficiency, as it is then that active and efficient competitors can deprive others of long-established market advantage. The following figure illustrates the user interactions during a model week: 


\section{$300 \%$}

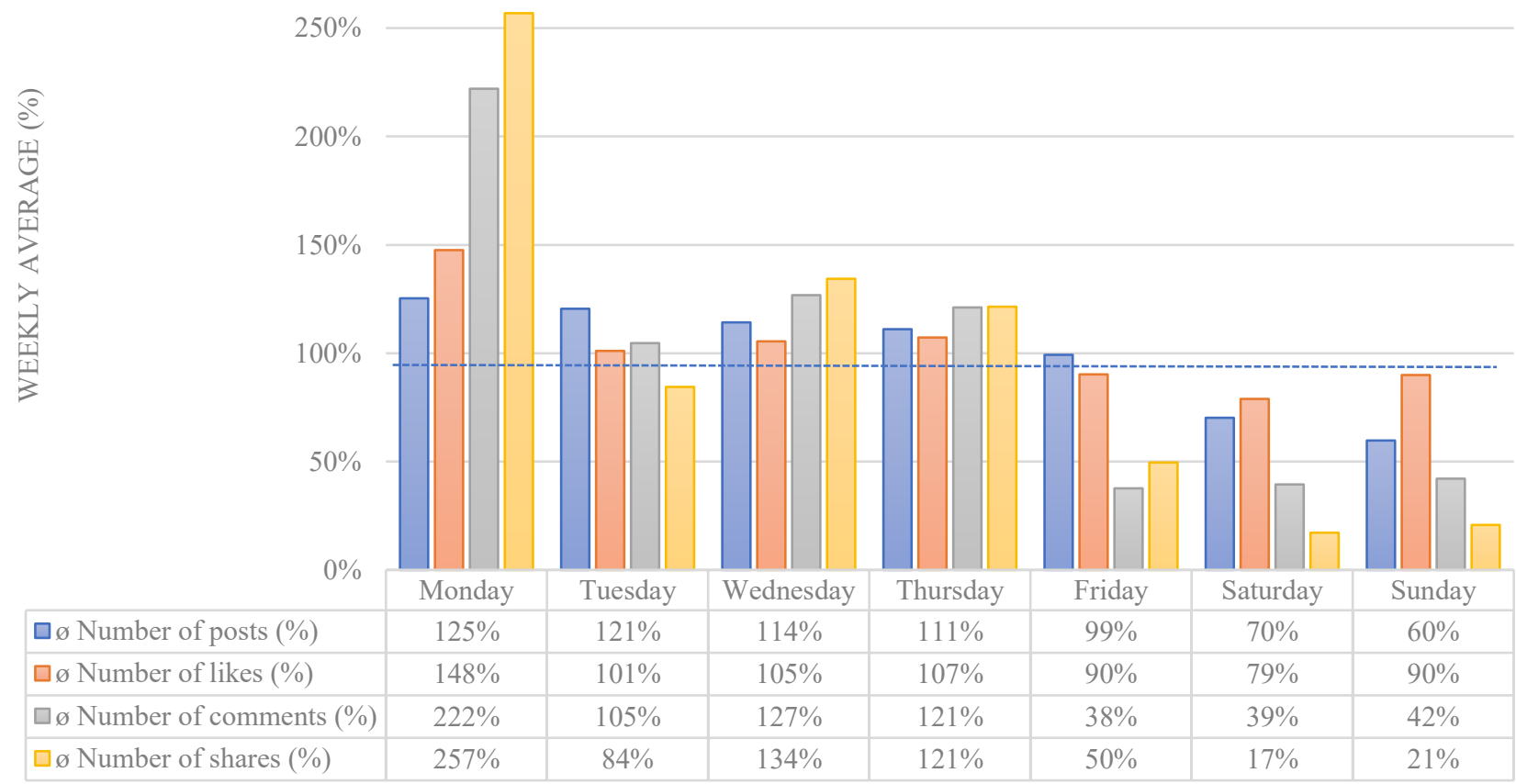

Figure 1. Interactions during a model week

Source: Authors.

The visualization presents user interactions from the perspective of a model week. The x-axis shows the types of the monitored interactions according to the day of the week. The y-axis shows the average cumulative frequencies for the observed interactions, whereby the dashed blue line indicates the level of the mean values with respect to the daily average calculated and presented in Table 1.

As can be seen from the graph of the model week, in terms of expected interactions to posts, the most numerous are on Mondays, which exceeds the daily averages for each of the monitored parameters. Of particular interest is the parameter "shares", which reaches $257 \%$ of the average weekly value. From the point of view of the parameter "shares", the least numerous is Saturday, which reaches just $17 \%$ of the average daily value of the parameter. In other words, from the point of view of the average relative frequency, shares on interactions posted on Saturday are $83 \%$ below the average of a normal week. From the point of view of the no less valuable indicator of interactions "comments", Monday is once again the best. In terms of average relative numbers, this is a little more than twice as powerful as the average daily value of the model week. In terms of ranking, Monday is followed by Wednesday and Thursday. This indicator has been identified in reference research in the past, so this is a recurring trend [19]. From the point of view of the "like" interaction, the most numerous Monday is followed by Thursday and Wednesday. In general, it is possible to observe the trend of a gradual decline in interactions at the end of the week, which can be described as positive with a significant dose of induction. The reason for this is that it may indicate that even during a pandemic, the model week retains the characteristics of the prepandemic period, whereby the arrival of the weekend sees the activity of users on social networks gradually decrease. This is especially visible when comparing Mondays and weekends, where the difference is enormous. As previously mentioned, this trend is also evident in previous research.

It is the shared opinion of the authors that there is a conflict with regards to work efficiency and time management at the beginning of the new week. Nevertheless, the model week in the pandemic and lockdown retains the parameters of the model week before the pandemic, which from the point of view of user preferences and habits can be evaluated as a positive phenomenon. At the same time, as can be seen in Figure 1, the activity of the subjects also declines with the arrival of the weekend, with the subjects conducting little more than half of the activity in terms of the number of posts compared to the weekly average.

Based on the findings presented, it can be stated that the values measured create a qualitative knowledge base for deeper quantitative research. The trends indicated in the discussion correlate with the trends identified in past research. The validity of the correlation will be tested in follow-up research. 


\section{Conclusion}

The specific conditions under which we carried out our analysis created almost a model situation for the fulfilment of the research aims. The investigation of the interactions of selected e-commerce entities provides opportunities for future comprehensive quantitative research. The e-commerce market has passed a stress test of unprecedented proportions. Almost overnight, this market had to replace the entire supply of traditional stores, which were forced to close their operations. The enormous pressure on the supply chain tested the stability of the system, whereby problems of an operational nature, but with strategic implications, were solved in real time. The supply and distribution of goods to customers, as well as customer service, are all physical aspects of trading on the Internet. From the point of view of the sample examined, it can be concluded that the processes were handled well. In general, it is possible to observe the trend of a gradual decline of interactions at the end of the week, which can be described as positive with a significant dose of induction. The reason for this is that it may indicate that even during a pandemic, the model week retains the characteristics of the pre-pandemic period, whereby the arrival of the weekend sees the activity of users on social networks gradually decrease. In the monitored period of 91 days, we recorded more than a quarter a million user interactions for a total of 668 posts published on the profiles of the subjects. If the total number of fans of the subjects is taken into account, it is possible to state that the user groups are relatively active. Active feedback not only brings opportunities in the form of real-time user information, but also a significant threat in the form of reputational risk [26-29], which can easily damage a brand. This is particularly true in the case of uncontrollable variables created by an atypical market situation. In this case, the managements of the e-commerce entities examined in our study can be rated positively. During the period under review, no significant crisis situation was noted in terms of user feedback in connection with the pandemic and the market situation. From the point of view of recorded interactions, it is possible to state that despite the stutters at the beginning of the lockdown, with increasing days, the processes were optimized in the desired direction. Positive interactions were maintained by the subjects in the form of competitions, whereas negative interactions mostly related to the longer delivery times for orders. An interesting innovation in marketing communication was applied by the Martinus internet bookstore, which initiated a relatively large group of followers to actively comment on their contributions through a game involving a superhero. We rate this more than positively, as we believe that innovation is the main driver of modern marketing management [30]. This also supports what Petr Drucker claims, that entrepreneurship has only two basic functions: marketing and innovation. Marketing and innovation produce results, everything else is a cost. At the end of this study, it can be stated that through the analysis of the data of the interactions of customer groups in a highly non-standard situation, it was possible to outline specific patterns of consumer behaviour, thereby creating a qualitative knowledge base for further research into the impact of the COVID-19 pandemic on national and international economies, for both economics and management sciences. With regards to the limitations of the research, the relatively limited sample may be an issue from the point of view of the object of research, i.e. the five largest subjects of e-commerce in the Slovak market. It is also considered necessary to carry out a further analysis in order to compare the period monitored with a similar period a year after the end of the pandemic.

\section{Acknowledgement}

This article is one of the partial outputs of the currently solved research grant VEGA no. 1/0240/20

\section{References}

1. R. Delina, M. Tkáč, Trust Building Mechanisms for Electronic Business Networks and Their Relation to eSkills, World Academy of Science. Engineering and Technology. 6(71), 380-390 (2010)

2. M. Maryška, P. Doucek, R. Kunstova, The Importance of ICT Sector and ICT university education for the economic development. 3rd international conference on new horizons in education - INTE 2012. 55, 1060-1068 (2012)

3. F. Reichheld, The Ultimate Question 2.0 (Revised and Expanded Edition): How Net Promoter Companies Thrive in a Customer-Driven World. Brighton: Harvard Business Review Press (2011)

4. M. A. Stec, P. B. Filip, M. Grzebyk, A. Pierscieniak, Socio-economic development in EU member states - concept and classifications. Engineering Economics. 25(5), (2014)

5. J. Straková, I. Rajiani, P. Pártlová, J. Váchal, J. Dobrovič, Use of the value chain in the process of generating a sustainable business strategy on the example of manufacturing and industrial enterprisescompanies in the Czech Republic. Sustainability (Switzerland). 12(4), 1520 (2020)

6. M. Fertik, D. Thomson, Wild West 2.0: How to Protect and Restore Your Reputation on the Untamed Social Frontier. New York: Amacom (2010)

7. J. Lee, S.-J. Kim, I. Kwon, Corporate social responsibility as a strategic means to attract foreign investment: Evidence from Korea. Sustainability. 9(11), 2121 (2017)

8. P. W. Holland, S. Leinhardt, Perspectives on Social Network Research. Cambridge: Academic Press (1979) 
9. G. L. Robins, Doing Social Network Research: Network-based Research Design for Social Scientists. London: SAGE Publications Ltd. (2015)

10. M. Boyd, N. Ellison. Social Network Sites, Definition, History, and Scholarship. Journal of Computer - Mediated Communication. 13(1) (2007)

11. J. Macek, Úvod do nových médii [Introduction to New Media]. Ostrava, Ostrava: Ostravská univerzita v Ostravě (2011)

12. V. Bednár̆, V. Internetová publicistika [Internet Journalism]. Praha: Grand Publishing (2011)

13. M. Petrusek, A. Vodáková, Velký sociologický slovník [Large sociological dictionary]. Praha: Karolinum (1996)

14. H. Kulhánková, J. Čamek, Fenomén facebook [Facebook Phenomenon]. Kladno, Kladno: Jakub Čamek (2010)

15. B. Wierzbinski, B. Communication and information sharing in the process of creating market advantage among small and medium enterprises collaboration. Hradec Economic Days 2014. Hradec Králové: Gaudeamus, 437-445 (2014)

16. N. T. Saruc, P. Dorčák, F. Pollák, E-business and its Application in Conditions of Central European Market. QIP journal. 17(1), (2013)

17. C. Shih, Vydělávajte na Facebooku: Jak využit sociální sítě k oslovení nových zákazníků, vytvoření lepšich produktů a zvýšeni prodeju [Make money on Facebook: How to use social networks to reach new customers, create better products and increase sales]. Brno: Computer Press (2010)

18. M. Zeisser, Unlocking the Exclusive Potential of Social Networks [online]. Available at: http://www.mckinseyquarterly.com/Unlocking_the_elusive_potential_of_social_networks_2623 (2013)

19. F. Pollák, P. Dorčák, The effective use of facebook by small and medium-sized enterprises operating in Slovakia. Market - Tržište. 28(1), 79-91(2016)

20. M. Karlíček, P. Král, Marketingová komunikace: jak komunikovat na našem trhu [Marketing communication: how to communicate in our market]. Praha: Grada Publishing (2011)

21. J. Soviar, Simplification of Marketing Scheme for Business Start-Ups. Communications - Scientific Letters of the University of Zilina, 13(4), 55-57 (2011)

22. M. Zamazalová, Marketing obchodní firmy [Business marketing]. Prague: Grada Publishing (2009)

23. R. Delina, Transparency in Electronic Business Negotiations - Evidence Based Aanalysis. Quality Innovation Prosperity. 8(2), 79-89 (2014)

24. F. Sudzina, P. Kmec, The technological paradox and evaluation of the benefits of informatization. Journal of Economics. 54(3), 281-293 (2006)

25. Ecommerce Bridge. The largest e-shops in Slovakia and in the world in 2019 [online]. Available at: https://www.ecommercebridge.sk/najvacsie-e-shopy (2020)

26. P. Dorčák, P. Markovič, F. Pollák, Multifactor analysis of online reputation as a tool for enhancing competitiveness of subjects from automotive industry. Journal of Economics. 65(2), 173-186 (2017)

27. F. Pollák, P. Dorčák, P. Markovič. Reputation Management, Promotion and Marketing Communications, U. Ayman, A. K. Kaya, London: IntechOpen. [online]. Available at: https://www.intechopen.com/books/promotion-andmarketing-communications/reputation-management (2019)

28. J. Vodak, M. Kubina, J. Soviar, D. Zraková, Online Reputation in Automotive. 18th International Scientific Conference on LOGI. Ceske Budejovice: MATEC Web of Conferences. 134(1), (2017).

29. D. Zrakova, M. Kubina, G. Koman, Influence of information-communication system to reputation management of a company. 12th International Scientific Conference of Young Scientists on Sustainable, Modern and Safe Transport. Procedia Engineering. 192, 1000-1005 (2017)

30. J. Straková, P. Pártlová, J. Váchal, M. Vochozka, Excellent top manager system (ETMS) - Quality management tool tertiary education. Proceedings of the 29th International Business Information Management Association Conference - Education Excellence and Innovation Management through Vision 2020: From Regional Development Sustainability to Global Economic Growth. 1844-1852 (2017) 